\title{
MOBILIZAÇÃO DO SOLO E PROFUNDIDADE DE SEMEADURA POR DIFERENTES MECANISMOS PARA O MANEJO DO SULCO DE SEMEADURA EM UMA SEMEADORA DIRETA
}

\section{EVANDRO M. BRANDELERO ${ }^{1}$, AUGUSTO G. DE ARAUJO², RICARDO RALISCH ${ }^{3}$}

RESUMO: Na semeadura direta, é fundamental que a mobilização do solo no sulco de semeadura seja a menor possível, visando a reduzir o risco de erosão e de desenvolvimento de ervas infestantes. O objetivo do trabalho foi avaliar o desempenho de diferentes mecanismos para o manejo do sulco de semeadura quanto à mobilização de solo e à profundidade de semeadura empregados em uma semeadora direta. O experimento foi conduzido em solo argiloso, em semeadura direta, com alto volume de palha de sorgo. Os tratamentos consistiam no emprego isolado de dois mecanismos rompedores à frente da haste sulcadora, compostos pelo disco de corte e rodas de varredura, e suas combinações com três mecanismos cobridores atrás do sulcador da semente, executados pelos discos cobridores, modelos vence-tudo, protótipo M1 e spider, sendo que a combinação disco de corte mais o modelo spider não foi avaliada devido à limitação de espaço físico. Após as análises dos resultados, constatou-se que o tratamento rodas de varredura operando isoladamente apresentou a maior área de solo mobilizada, com $105 \mathrm{~cm}^{2}$, e a associação dos mecanismos disco de corte mais o protótipo M1 apresentaram os menores valores, com 35,3 cm². Avaliando-se no conjunto de dados, observam-se ganhos de empolamento quando se adicionaram mecanismos cobridores aos rompedores rodas de varredura e ao disco de corte de, no mínimo, 10\% e $26 \%$, respectivamentes, melhorando a profundidade das sementes de milho em até 0,013 e 0,011 metros, respectivamentes. Já o mecanismo rompedor disco de corte e suas associações com as cobridoras modelo vence-tudo e protótipo M1 foram os que obtiveram maior aprofundamento das sementes, bem como a menor mobilização de solo no interior do sulco e maiores retornos de solo pelos cobridores.

PALAVRAS-CHAVE: Zea mays, plantio direto, mecanização agrícola, sulcadores.

\section{SOIL MOBILIZATION AND SEEDING DEPTH BY NO-TILL SEEDER MECHANISMS FOR RESIDUE MANAGEMENT}

\begin{abstract}
Decreasing soil mobilization in no-till is essential in order to reduce the risk of soil erosion and the development of weeds. The objective was to evaluate soil mobilization and seeding depth by the action of mechanisms for residue management in the seeding row of a direct seeder. The experiment was conducted in a clay soil under no-tillage with $10.7 \mathrm{Mg} \mathrm{ha}^{-1}$ of sorghum residue mechanically managed. The experiment had seven treatments composed by the combination of two mechanisms ahead of the shank, (flat cutting disc and row cleaners) and three mechanisms behind the double discs (disks covering models "vence-tudo", M1 and Spider). The results showed the row cleaners without any covering mechanism had the highest soil mobilization area $\left(105 \mathrm{~cm}^{2}\right)$ and the combination of flat cutting disc with M1 had the lowest value $\left(35.3 \mathrm{~cm}^{2}\right)$. Evaluating the data set, there are shoaling gains when added coverer mechanisms to the row cleaners and the cutting disc at least $10 \%$ and $26 \%$, respectively, improving the depth of the corn seed to 0.013 and 0.011 meters, respectively. But the breaker blade mechanism and their association with the covering models "vence-tudo" and M1 prototype were the ones that had the further deepening of the seeds and the lower mobilization soil inside the furrow and greater soil returns by the coverers.
\end{abstract}

KEYWORDS: Zea mays, no-tillage, agricultural mechanization, furrowers.

\footnotetext{
${ }^{1}$ Eng $^{\circ}$ Agrônomo, Professor, Universidade Tecnológica Federal do Paraná, Dois Vizinhos - PR, ebrandelero@utfpr.edu.br

${ }^{2}$ Eng ${ }^{\circ}$ Agrícola, Pesquisador, Instituto Agronômico do Paraná, Londrina -PR, agaraujo@iapar.br

${ }^{3}$ Eng $^{\circ}$ Agrônomo, Professor Associado, Universidade Estadual de Londrina, Londrina - PR, ralisch@uel.br

Recebido pelo Conselho Editorial em: 12-4-2012

Aprovado pelo Conselho Editorial em: 25-11-2013
} 


\section{INTRODUÇÃO}

Na agricultura sustentável, é essencial considerar a conservação do solo e da água, pois a substituição de ambientes naturais por uma agricultura com uso intensivo do solo contribui para alterações consideráveis na dinâmica dos ecossistemas (ANDRADE et al., 2009). Uma alternativa adequada para a minimização dos impactos ambientais da agricultura é o Sistema do Plantio Direto (SPD) (FRABETTI et al., 2011).

No SPD, a semeadura é realizada por máquinas denominadas de semeadoras diretas, as quais realizam o preparo localizado do sulco utilizando mecanismos rompedores para transpor a palha e a deposição de adubos e sementes, bem como mecanismos de cobertura para melhorar a deposição da palha e do solo sobre o sulco anteriormente mobilizados, agindo positivamente no ambiente germinativo das sementes (MAHL et al., 2008). Tais mecanismos de manejo do sulco, como os de cobertura, proporcionam efeitos diferenciados na linha, modificando o ambiente físico do solo quanto à área mobilizada e a profundidade das sementes (FALLAHI \& RAOUFAT, 2008). Os mecanismos rompedores mais utilizados são os discos planos para o corte da palha para o manejo do sulco, localizado à frente da haste sulcadora de adubo (ANDREOLLA \& GABRIEL FILHO, 2006).

Uma alternativa aos mecanismos rompedores discos planos são as rodas de varredura, que afastam lateralmente a palha ao invés de cortá-las, como ocorre nos discos, utilizando duas rodas dentadas engrenadas e convergentes (FALLAHI \& RAOUFAT, 2008). O deslocamento da palha para a lateral da linha de semeadura favorece o ambiente germinativo para as sementes por reduzir a introdução de palha no interior do sulco, melhorando o contato solo-semente e garantindo boa germinação (BRANDELERO, 2009). Entretanto, a ausência da cobertura sobre o solo favorece a perda de água para a atmosfera (ANDRADE, 2010), aumenta a incidência de ervas daninhas (THEISEN \& BIANCHI, 2010) e favorece o processo erosivo do solo pela água da chuva (CARVALHO, 2009).

Além dos efeitos dos mecanismos rompedores que mobilizam o solo no interior do sulco, também há possibilidade da adição de mecanismos de cobertura para o retorno do solo e da palha anteriormente mobilizados (CASÃO JUNIOR \& SIQUEIRA, 2006; BRANDELERO, 2009). A utilização de mecanismos de cobertura para o retorno do solo sobre o sulco anteriormente removido pelos sulcadores, também denominado de "aterradores", aumenta a profundidade das sementes, reduzindo a porcentagem de sementes expostas e melhorando a população de plantas (CASÃO JUNIOR \& SIQUEIRA, 2006). Também, o emprego de mecanismos de cobertura contribui não só com a reposição de solo sobre o sulco, mas também o de palha anteriormente removida pelos sulcadores, reduzindo as oscilações da temperatura e das perdas de água, o que irá proporcionar a melhoria da qualidade da semeadura (BRANDELERO, 2009).

A utilização de diferentes mecanismos rompedores à frente da linha da semeadora, como o disco liso e as rodas de varredura, poderá limitar a profundidade de semeadura por mobilizar solo para fora do sulco. Entretanto, este problema poderá ser amenizado com a adição dos mecanismos de cobertura por recolocarem solo sobre as sementes, melhorando a profundidade de semeadura.

O objetivo do trabalho foi avaliar o desempenho de diferentes mecanismos para o manejo do sulco de semeadura quanto à mobilização de solo e à profundidade de semeadura, empregados em uma semeadora direta.

\section{MATERIAL E MÉTODOS}

O trabalho foi conduzido na área experimental do Instituto Agronômico do Paraná (IAPAR), de Londrina - PR - Brasil, a $23^{\circ} 37^{\prime}$ S e $51^{\circ} 17^{\prime}$ W. O solo foi classificado como Latossolo Vermelho distroférrico e encontrava-se sob o Sistema Plantio Direto (SPD) há 21 anos. A densidade média do solo na ocasião da implantação era de $1,25 \mathrm{Mg} \mathrm{m}^{-3}$, na profundidade entre 0,025 e 0,075 m e de $1,36 \mathrm{Mg} \mathrm{m}^{-3}$ na profundidade entre 0,1 e $0,15 \mathrm{~m}$. Já o conteúdo de água volumétrico médio do solo 
foi de 30,7\% na profundidade entre 0,025 e $0,075 \mathrm{~m}$ e de $36,3 \%$ na profundidade entre 0,1 e $0,15 \mathrm{~m}$. Tanto para a densidade como para o conteúdo de água volumétrico, seguiram-se os procedimentos descritos pela EMBRAPA (1997).

O experimento foi implantado em uma área com cobertura de palha de sorgo, na dose de 10,7 $\mathrm{Mg} \mathrm{ha}^{-1}$ de massa seca, manejada com triturador de resíduos vegetais. Para a operação de semeadura, foi utilizado um trator marca Agrale, modelo 5085.4, com sistema de tração 4x2, com TDA ligada, potência de 62,5 kw (85 CV), massa de $4.420 \mathrm{~kg}$, trabalhando na primeira marcha simples e rotação no motor de $1.500 \mathrm{rpm}$, proporcionando velocidade média de $5,7 \mathrm{~km} \mathrm{~h}^{-1}$.

Para a implantação dos tratamentos, utilizou-se de uma linha de uma semeadora direta marca Jumil, com a seguinte configuração: sulcador de fertilizante tipo haste, sulcador de semente tipo disco duplo defasado, roda controladora de profundidade de semente e roda compactadora lisa.

O experimento foi implantado no delineamento de blocos casualizados, com quatro repetições e sete tratamentos, sendo que os tratamentos consistiram no emprego isolado de dois mecanismos rompedores à frente da haste sulcadora, compostos pelo disco de corte e por rodas de varredura, e na combinação de três mecanismos cobridores atrás do sulcador da semente, executados pelos discos cobridores, modelos vence-tudo, protótipo M1 e spider, sendo que a combinação disco de corte e modelo spider não foi avaliada devido à limitação de espaço físico. As parcelas experimentais foram constituídas por uma linha de semeadura com $30 \mathrm{~m}$ de comprimento e distanciadas $3 \mathrm{~m}$ entre si. A semente de milho foi a cultivar AG1051, na quantidade de 8 sementes por metro.

O mecanismo disco de corte foi composto por um disco metálico plano e liso, localizado anteriormente aos demais componentes ativos da semeadora, e desempenhava a função de corte da palha, utilizando o solo como anteparo (Figura 1-A). Já o mecanismo rodas de varredura (RV) era constituído por duas rodas metálicas lisas que possuíam, ao longo de sua borda, pontas em bisel, trabalhando engrenadas e movimentando-se pelo contato das pontas com o solo. Ao operarem, as RV's deslocavam a palha para a lateral da linha de semeadura, sem cortá-la (Figura 1-B).

Os conjuntos de mecanismos cobridores visavam a deslocar solo da lateral para o centro da linha após a passagem do DC ou RVs (Figura 1-C, D, e E), sendo posicionados lateralmente e após o sulcador de sementes em posição oblíqua ao deslocamento da semeadora, um de cada lado da linha de semeadura. Os modelos variaram quanto ao formato da ferramenta. O modelo vence-tudo era composto de dois discos metálicos côncavos, com borda lisa (Figura 1-C). Os discos cobridores, modelo protótipo M1, eram dois discos metálicos lisos com reentrâncias semicirculares, formando uma borda recortada, distanciados entre si e posicionados em direção oblíqua em relação à linha de semeadura (Figura 1-D). Os discos cobridores, modelo spider, eram dois discos metálicos lisos, similares aos das RVs, porém posicionados de modo a trazer solo e palha para cobrir a linha de semeadura (Figura 1-E). 

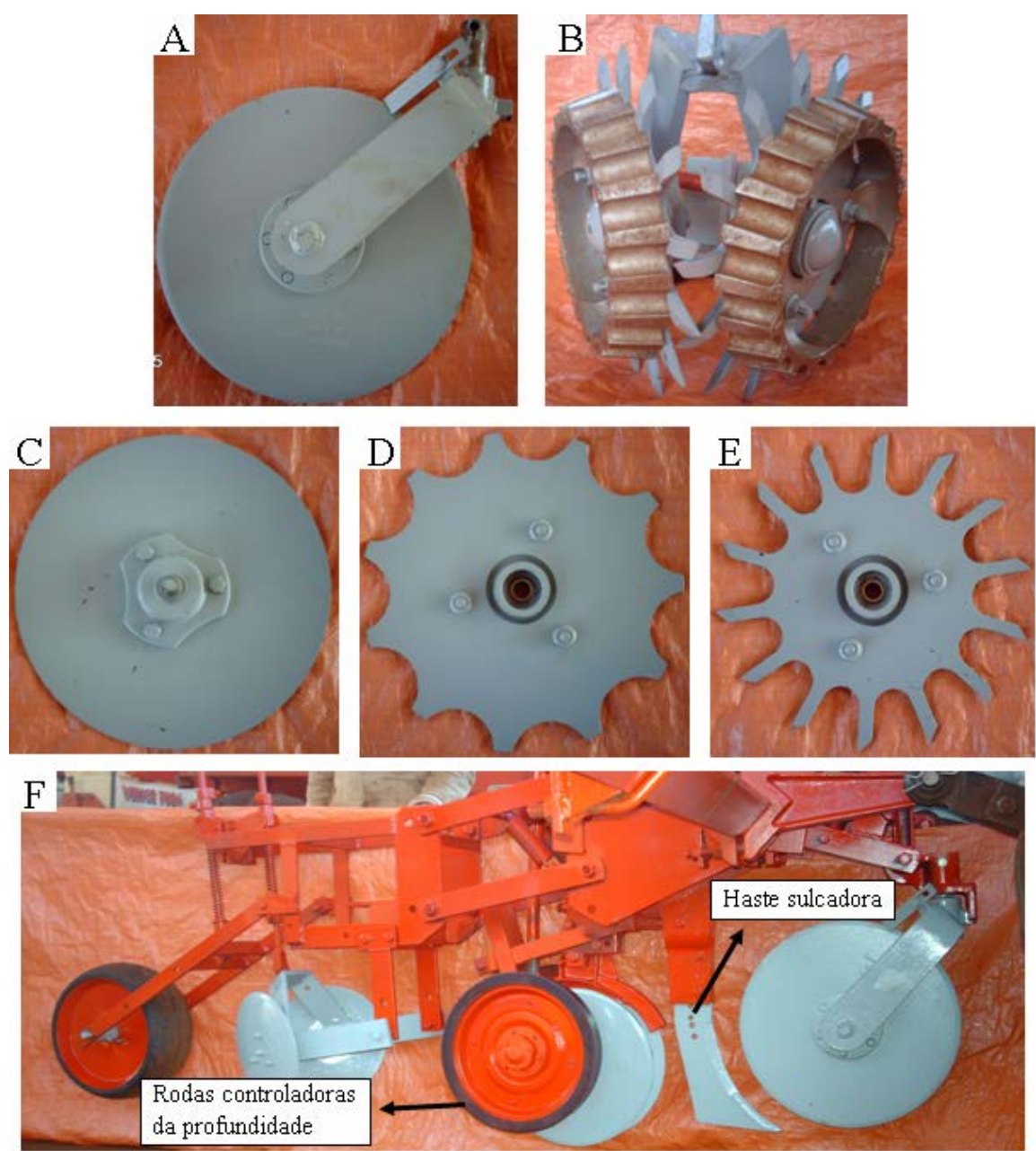

FIGURA 1. Mecanismos para o manejo do sulco em semeadora direta, sendo: A (disco de corte liso, DC); B (rodas de varredura, RV); C (discos cobridores modelo vence-tudo); D (rodas cobridoras modelo protótipo M1); E (rodas cobridoras modelo spider), e F (disposição geral da localização dos mecanismos usados na semeadora direta). Devices for furrow handling with no-till seeder: A (smooth coulter, SC); B (row cleaners, RC); C (vence tudo model cover disks); D (prototype M1 model cover wheels); $\mathrm{E}$ (spider model cover wheels) and $\mathrm{F}$ (general arrangement of the devices used with the no-till seeder).

Para avaliar os efeitos da mobilização de solo no sulco de semeadura, foram avaliados a área mobilizada e de elevação, a profundidade e a largura máxima, medidas com o uso de um perfilômetro de varetas com largura útil de $0,9 \mathrm{~m}$, e 60 pontos de leituras espaçadas a 0,015 m (Figura 2).

Efetuaram-se duas leituras transversais de perfilometria por parcela, em locais previamente demarcados com piquetes no solo, que permitiram o apoio da superfície de referência para medição dos perfis. Foram realizadas leituras do perfil do solo antes da aplicação dos tratamentos, obtendo-se o perfil natural, e após a aplicação dos tratamentos, para obtenção do perfil da superfície do solo pós-semeadura e do perfil do solo mobilizado, denominados, respectivamente, de perfil de elevação e perfil de fundo (CARVALHO FILHO et al., 2007). Para a avaliação do perfil de fundo, foi removido manualmente o solo mobilizado, tomando-se cuidado para não descaracterizar o efeito do mecanismo. Para quantificar a área mobilizada, subtraíram-se os dados dos perfis naturais dos perfis de fundo, a cada posição, e para a área de elevação, subtraíram-se os resultados dos perfis naturais dos perfis de elevação. A profundidade e a largura máxima do sulco foram extraídas, 
considerando-se a maior diferença entre os perfis da superfície original e interno do solo no sulco (CARVALHO FILHO et al., 2007)

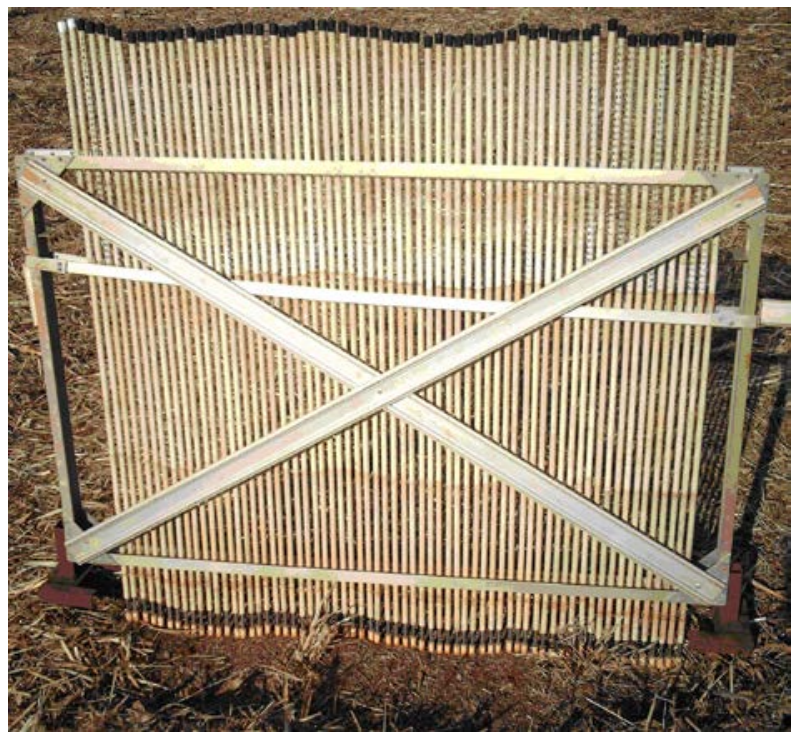

FIGURA 2. Perfilômetro utilizado para avaliar os efeitos no sulco de semeadura em função dos mecanismos, em semeadura direta. Perfilometry meter used to evaluate the effects of the seed furrows according to the mechanisms in the no-till method.

Para a avaliação do empolamento do solo, seguiu-se a metodologia sugerida por CARVALHO FILHO et al. (2007), com adaptações às condições do experimento. O empolamento do solo mostra a porcentagem do aumento do volume do solo mobilizado pelos mecanismos de cobertura. O empolamento do solo foi determinado, utilizando a equação 1, que estabelece a razão entre a área de elevação e a área mobilizada pelos mecanismos, multiplicado por 100, quantificados pelo perfilômetro, descritos anteriormente.

$$
\mathbf{E m}=\left(\frac{A_{e}}{A_{m}}\right) 100
$$

em que,

Em - empolamento, \%;

$A_{e}$ - área de elevação, m², e

$\mathrm{A}_{\mathrm{m}}$ - área mobilizada, $\mathrm{m}^{2}$.

A profundidade das sementes foi determinada, coletando-se dez plântulas por parcela após a emergência, medindo-se a distância entre a base do hipocótilo da semente, localizado na própria semente e no interior do sulco de semeadura, até o início da parte superior do colmo, localizado fora do solo, onde se iniciava a presença de clorofila (BRANDELERO, 2009).

Após as coletas dos dados, os valores foram submetidos ao Teste de Levene para verificar a homocidasticidade. Posteriormente, efetuou-se análise da variância e, quando houve diferença significativa a $5 \%$ de probabilidade de erro, suas médias foram comparadas entre si, pelo teste de Tukey, a 5\%, utilizando o programa Statistica Versão 6.1.

\section{RESULTADOS E DISCUSSÃO}

Os tratamentos apresentaram distintos efeitos na profundidade máxima do sulco da semeadura, sendo que os mecanismos que apresentaram disco de corte (DC) à frente atuaram, em média, a 0,052 m contra 0,075 m para as rodas de varredura (RV) (Tabela 1 e Figura 3). 
TABELA 1. Quantificação da mobilização do solo e profundidade de semeadura por mecanismos para o manejo do sulco de semeadura, sendo: profundidade máxima do sulco (P.máx.), largura máxima do sulco (L.máx.), área mobilizada (Am), área de elevação (Ae), empolamento (Em), profundidade das sementes (Prof. Sem.). Quantification of soil mobilization and sowing depth according to the mechanisms in the seed furrow, being: maximum furrow depth (D. max.), maximum furrow width (W. max.), mobilized area (Ma), elevation area (Ea), swelling (Sw), Seed depth (S. Depth).

\begin{tabular}{lllllll}
\hline Tratamentos & P.máx. & L.máx. & $\mathrm{Am}$ & $\mathrm{Ae}$ & $\mathrm{Em}$ & Prof. Sem. \\
\hline & $\mathrm{m}$ & $\mathrm{m}$ & $\mathrm{cm}^{2}$ & $\mathrm{~cm}^{2}$ & $\%$ & $\mathrm{~m}$ \\
DC+VT & $0,054 \mathrm{bc} *$ & $0,176 \mathrm{~b}$ & $40,5 \mathrm{c}$ & $19,3 \mathrm{a}$ & $47,7 \mathrm{a}$ & $0,039 \mathrm{a}$ \\
DC+M1 & $0,049 \mathrm{c}$ & $0,165 \mathrm{~b}$ & $35,3 \mathrm{c}$ & $12,6 \mathrm{bc}$ & $35,6 \mathrm{a}$ & $0,043 \mathrm{a}$ \\
DC & $0,054 \mathrm{bc}$ & $0,184 \mathrm{ab}$ & $45,6 \mathrm{c}$ & $4,3 \mathrm{~d}$ & $9,5 \mathrm{~b}$ & $0,032 \mathrm{~b}$ \\
RV+VT & $0,071 \mathrm{ab}$ & $0,231 \mathrm{ab}$ & $70,7 \mathrm{~b}$ & $10,1 \mathrm{bc}$ & $14,3 \mathrm{~b}$ & $0,035 \mathrm{~b}$ \\
RV+M1 & $0,071 \mathrm{ab}$ & $0,221 \mathrm{ab}$ & $72,5 \mathrm{~b}$ & $9,6 \mathrm{c}$ & $13,2 \mathrm{~b}$ & $0,030 \mathrm{~b}$ \\
RV+MS & $0,081 \mathrm{a}$ & $0,238 \mathrm{ab}$ & $80,9 \mathrm{~b}$ & $15,0 \mathrm{ab}$ & $18,5 \mathrm{~b}$ & $0,036 \mathrm{~b}$ \\
RV & $0,079 \mathrm{a}$ & $0,279 \mathrm{a}$ & $105 \mathrm{a}$ & $3,3 \mathrm{~d}$ & $3,1 \mathrm{c}$ & $0,023 \mathrm{c}$ \\
C.V. \% & 13,88 & 20,17 & 14,92 & 31,36 & 19,95 & 12,25 \\
\hline
\end{tabular}

*Médias seguidas por letras distintas em cada coluna diferem significativamente, pelo teste de Tukey, a 5 \%. C.V., coeficiente de variação, \%.

A maior profundidade máxima ocorreu com o tratamento RV+MS, tendo atingido $0,081 \mathrm{~m}$ (Tabela 1). O tratamento DC+M1 apresentou a menor média de profundidade, com 0,049 m na profundidade máxima atingida, a qual diferiu significativamente de todos os tratamentos que apresentaram rodas de varredura à frente, porém não diferiu dos tratamentos que tinham em sua composição DC. Estes resultados estão abaixo dos obtidos por SANTOS et al. (2008), avaliando três semeadoras com haste sulcadora no SPD, em solo argiloso, na cultura do milho, os quais obtiveram profundidade média entre 0,05 e 0,06 m, considerando profundidades satisfatórias, porém não atingidas no presente estudo (Tabela 1). Entretanto, PALMA (2013), avaliando diferentes profundidades e ponteiras em hastes sulcadoras, obteve valores superiores ao presente trabalho, sendo estes entre 0,121 e $0,184 \mathrm{~m}$. A baixa profundidade do sulco obtida no presente trabalho pode estar ligada ao baixo peso da máquina semeadora por possuir apenas uma linha de semeadura para testes e não dispor de dispositivo para o controle da pressão sobre a linha encontrada em máquinas comerciais.

Já a menor profundidade obtida nos mecanismos que apresentaram disco de corte em sua composição deve-se, segundo LEVIEN et al. (2011), à forma de atuação do disco que, ao se deslocar, comprime o solo e fica mais sujeito às interferências de resíduos no momento da abertura do sulco, o que dificulta seu aprofundamento. Como alternativa a este efeito, as rodas de varredura afastam lateralmente a palha ao invés de cortá-la, utilizando duas rodas engrenadas e dentadas (BRANDELERO, 2009).

Para a largura máxima do sulco (Tabela 1), o tratamento RV proporcionou 0,279 m, diferindo $(\mathrm{P}, 0,05)$ dos tratamentos DC+VT com 0,176 m e do DC+M1 com 0,165 m. Possivelmente, os efeitos da maior largura no sulco, dos tratamentos com rodas de varredura em comparação aos mecanismos compostos de discos de corte, devem-se à forma de atuação dos mecanismos junto ao solo, sendo que as rodas de varredura, para serem acionadas, devem ter bom contato com o solo, que ao se deslocarem engrenadas (Figura 1-B) resultam em maior área de contato com o solo. Outra diferença importante é o sistema de ação entre os mecanismos que manejam o sulco com a superfície do solo, pois, no caso do disco de corte, este penetra a superfície do solo ao cortar a palha, rompendo a estrutura superficial do solo e condicionando a ruptura que é promovida pelo sulcador, eventualmente atenuando a propagação das linhas de ruptura das estruturas do solo (REICHERT et al., 2010). 

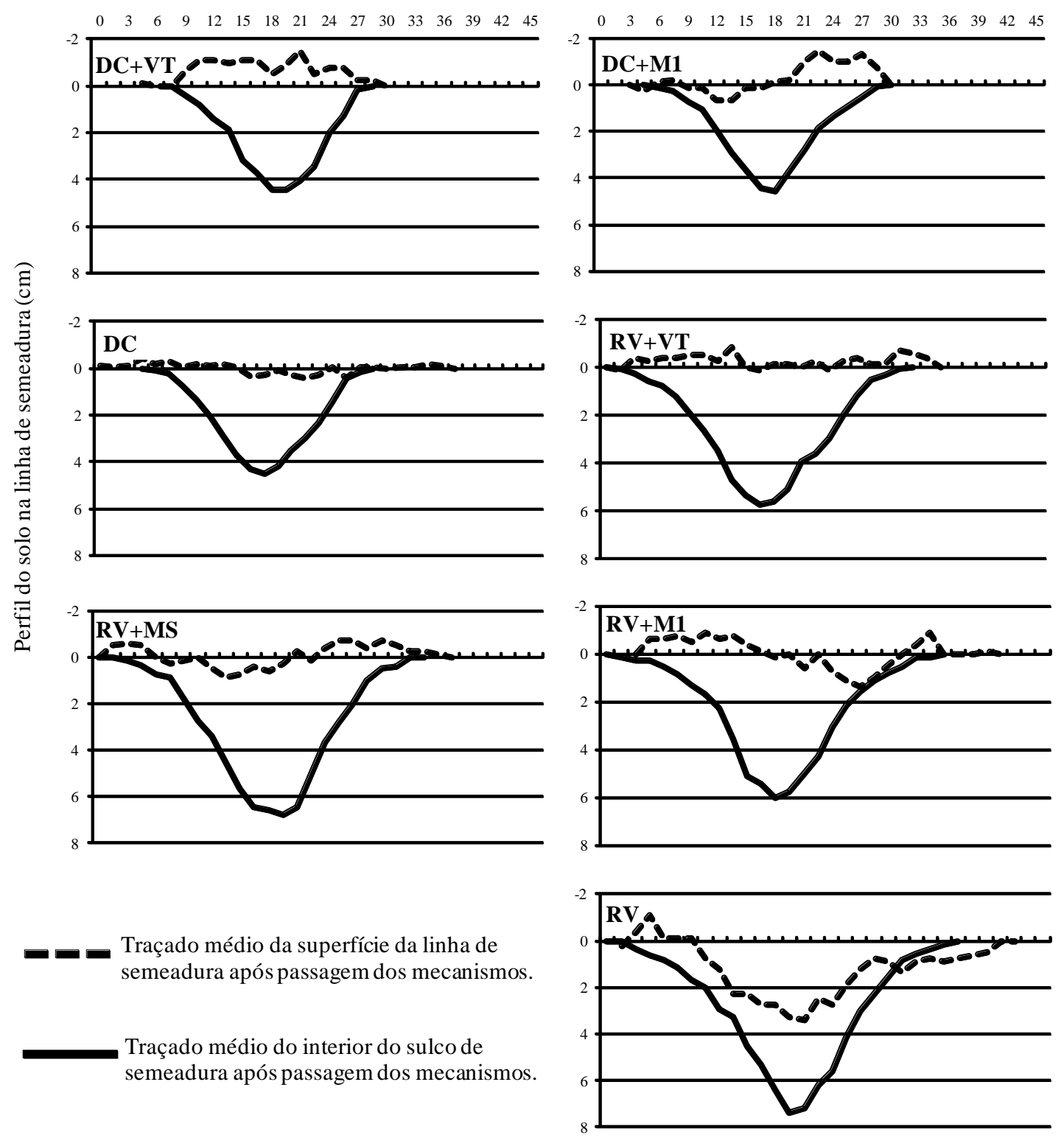

FIGURA 3. Perfilometria do sulco após a passagem dos mecanismos para o manejo do sulco de semeadura, sendo que: linha tracejada correspondente à superfície e a linha contínua correspondente ao interior do sulco. Perfilometry of the furrow after the use of mechanisms in the seed furrow: the dashed line corresponds to the surface and the solid line corresponds to inner of the furrow.

Notam-se, na Figura 3, os efeitos da haste sulcadora associados aos diferentes mecanismos colocados à sua frente, demonstrando que a forma de ação dos sulcadores depende de como a palha é manejada. As diferenças obtidas na área mobilizada devem-se às maiores profundidades e maiores larguras superficiais dos sulcos formados nos tratamentos RV e suas associações, também constatadas por FALLAHI \& RAOUFAT (2008).

O tratamento RV apresentou a maior área de solo mobilizada com $105 \mathrm{~cm}^{2}$, diferindo dos demais (Tabela 1), sendo que o tratamento DC+M1 apresentou menores valores médios absolutos com 35,3 $\mathrm{cm}^{2}$, porém não diferenciaram significativamente dos tratamentos DC+VT e DC. CEPIK et al. (2010), avaliando a mobilização de solo por uma haste sulcadora sob a condição de diferentes doses de palha de culturas de inverno, no SPD, obtiveram valores entre 59,3 e 68,7 cm², próximos aos de RV+VT e superiores a todos os tratamentos com DC à frente da haste sulcadora. Segundo 
FALLAHI \& RAOUFAT (2008), a área mobilizada poderá aumentar quando a palha está presente em volume reduzido.

Observa-se que todos os tratamentos que apresentam disco de corte à frente do sulcador resultaram em áreas mobilizadas significativamente menores em comparação aos que possuíam rodas de varredura à frente (Tabela 1), denotando que a forma como a cobertura é tratada pelos mecanismos rompedores interfere na forma de ação dos sulcadores. Os valores de área mobilizada demonstraram haver diferentes efeitos nos dois mecanismos rompedores empregados, sendo que a RV propiciou sempre maiores valores, assim como a associação destes com os mecanismos de cobertura avaliados, o que não é bom quando se pensa em termos conservacionistas com base nos princípios de baixa mobilização de solo no SPD. A maior área mobilizada de solo pelas rodas de varredura pode estar ligada à maior superfície específica em contato com o solo, provocando maior resistência do sulcador ao rolamento (SANTOS et al., 2010), bem como resultando em sulcos mais largos e com maiores mobilizações de solo (SIQUEIRA \& CASÃO JÚNIOR, 2004).

Os valores de área mobilizada no sulco foram sempre menores quando se adicionaram cobridores a RV, possivelmente resultante da diferença de distribuição da pressão da linha sobre o solo, tanto menor quanto maior a área de contato, considerando que, para o ensaio em questão, optou-se por padronizar esta pressão para todos os tratamentos, através do mecanismo específico da máquina.

Os dados de área de elevação representam a área de solo que retornou sobre o sulco pelos mecanismos de cobertura empregados, diferenciando-se dos tratamentos em que tais mecanismos não foram empregados (Tabela 1). Os resultados de empolamento e área de elevação distinguiramse entre os mecanismos para o manejo do sulco de semeadura, confirmando que o modo de se manejar a palha pelos mecanismos rompedores altera significativamente a forma de ação do sulcador de haste empregado na semeadora, haja vista o menor valor de empolamento obtido pelo tratamento RV. Este resultado contrasta com o dado de área mobilizada, onde o referido tratamento obteve o maior valor, porém, explica-se pela maior largura máxima obtida. Portanto, com a retirada da palha da superfície do solo pela RV, o sulcador promoveu uma ruptura de solo mais horizontal, e o deslocamento desta palha para a lateral induziu a uma ruptura mais vertical no solo. Esta diferença de forma de ação pode ainda não estar associada à palha propriamente dita, mas aos diferentes efeitos dos mecanismos DC e RV na superfície do solo.

Constatou-se que os mecanismos de cobertura adicionados ao DC e à RV contribuem para o retorno do solo, resultando em aumento de, no mínimo, $10 \%$ no empolamento observado nos mecanismos que apresentaram rodas de varredura em sua composição, e de $26 \%$ nos mecanismos que apresentaram disco de corte (Tabela 1). Os tratamentos que melhor desempenharam a função de retorno de solo sobre a linha foram o DC+VT, $D C+M 1$ e $R V+M S$, o que pode ser indicativo de qualidade de acabamento de semeadura.

Na avaliação da profundidade de semente, constata-se que o tratamento que mais a aprofundou foi o DC+M1, o qual obteve a maior valor médio $(0,043 \mathrm{~m})$, diferindo de todos os demais, com exceção do DC+VT (Tabela 1). Estes resultados assemelham-se aos encontrados por KOAKOSKI et al. (2007) com o mecanismo rompedor do tipo disco duplo (0,044 m), mas abaixo dos valores encontrados por esses autores para o sulcador de haste $(0,0501 \mathrm{~m})$. O tratamento RV apresentou a menor profundidade das sementes, com 0,023 m, estando inferior aos padrões técnicos da cultura do milho que estão entre 0,03 a 0,05 metros (CRUZ et al., 2013). ARATANI et al. (2006), avaliando o desempenho de uma semeadora em solo muito argiloso com palha intacta de milho, constataram que sementes mal cobertas por solo ou depositadas sobre sua superfície prejudicam o estabelecimento da população desejada de plantas. Possivelmente, a menor profundidade das sementes no tratamento RV venha a prejudicar a germinação das sementes e a comprometer a população final de plantas.

Observa-se que a adição de mecanismos de cobertura nos tratamentos que continham rodas de varredura contribuiu com o retorno de solo sobre as sementes em até 0,013 metros na profundidade 
das sementes, quando comparada à profundidade do tratamento RV operando isoladamente com o tratamento com rodas de varredura adicionado do cobridor spider (Tabela 1). Isso demonstrando que semeadoras equipadas com rodas de varredura necessitam da adição de mecanismos cobridores para melhorar a profundidade de semeadura.

\section{CONCLUSÕES}

Os mecanismos rompedores denominados rodas de varredura apresentaram maior área mobilizada de solo em relação aos mecanismos com disco de corte, o que não é bom quando se pensa nos princípios conservacionistas de baixa área mobilizada de solo no sistema do plantio direto.

A maior área mobilizada de solo no sulco de semeadura pelas rodas de varredura demonstrou a necessidade da complementação com mecanismos de cobertura para o retorno de solo sobre o sulco, contribuindo no aumento da profundidade das sementes.

Os diferentes mecanismos rompedores e cobridores do sulco de semeadura interferiram diretamente na qualidade da operação da semeadura, sendo recomendável o uso dos cobridores para a melhoria da profundidade de semeadura.

O mecanismo rompedor de disco de corte e suas associações com as cobridoras modelo vence-tudo e protótipo M1 foram os que obtiveram maior aprofundamento das sementes, bem como a menor mobilização de solo no interior do sulco e maiores retornos de solo pelos cobridores.

\section{AGRADECIMENTOS}

Esta pesquisa foi realizada com o apoio financeiro do Conselho Nacional de Desenvolvimento Científico e Tecnológico - CNPq. O primeiro autor também agradece à Universidade Estadual de Londrina, por meio do Programa de Pós-Graduação em Agronomia, pela oportunidade para a obtenção do título de Doutor, bem como ao Instituto Agronômico do Paraná - IAPAR, pelo apoio na confecção e execução do projeto da Tese.

\section{REFERÊNCIAS}

ANDRADE, J.G. Influência dos resíduos vegetais na superfície do solo na dinâmica de evaporação da água e temperatura do solo. 2010. 92f. Dissertação (Mestrado em Ciência do Solo) Universidade Federal de Santa Maria, Santa Maria, 2010.

ANDRADE, R.S.; STONE, L.F.; SILVEIRA, P.M. da Culturas de cobertura e qualidade física de um Latossolo em plantio direto. Revista Brasileira Engenharia Agrícola e Ambiental, Campina Grande, v.13, n.4, 2009.

ANDREOLLA, V.R.M; GABRIEL FILHO, A. Demanda de potência de uma semeadora com dois tipos de sulcadores em áreas compactadas pelo pisoteio de animais no sistema integração lavourapecuária. Engenharia Agrícola, Jaboticabal, v.26, n.3, p.768-776, 2006.

ARATANI, R.G.; MARIA, I.C. de; CASTRO, O.M. de; PECHE FILHO, A.; DUARTE, A.P.; KANTHACK, R.A.D. Desempenho de semeadoras-adubadoras de soja em Latossolo Vermelho muito argiloso com palha intacta de milho. Revista Brasileira de Engenharia Agrícola \& Ambiental, Campina Grande, v.10, n.2, p.517-522, 2006.

BRANDELERO, E.M. Manejo da palha na linha em semeadura direta. 2009. 82f. Tese. (Doutorado em Agronomia) - Centro de Ciências Agrárias, Universidade Estadual de Londrina, Centro de Ciências Agrárias, Londrina, 2009.

CARVALHO FILHO, A.; CENTURION, J.F.; SILVA, R.P. DA; FURLANI, C.E.A.; CARVALHO, L.C.C. Métodos de preparo do solo: alterações na rugosidade do solo. Engenharia Agrícola, Jaboticabal, v.27, n.1, p.229-237, 2007. 
CARVALHO, M.A.R. de Efeito da cobertura do solo e de práticas de controle de erosão nas perdas de água e solo por escoamento superficial. 2009. 120f. Tese (Doutorado em Irrigação e Drenagem) - Escola Superior de Agricultura Luiz de Queiroz, Universidade de São Paulo (USP), Piracicaba, 2009.

CASÃO JUNIOR, R.; SIQUEIRA, R. Máquinas para manejo de vegetação e semeadura em plantio direto. In.: CASÃO JUNIOR, R.; SIQUEIRA, R.; MEHTA, Y. R.; PASSINI, J.J. Sistema plantio direto com qualidade. Londrina: IAPAR, 2006, p.85-126.

CEPIK, C.T.C.; TREIN, C.R.; LEVIEN, R.; CONTE, O. Força de tração e mobilização do solo por hastes sulcadoras de semadoras-adubadoras. Revista Brasileira Engenharia Agrícola \& Ambiental, Campina Grande, v.14, n.5, p.561-566, 2010.

CRUZ, J.C.; PEREIRA FILHO, I.A.; ALBUQUERQUE FILHO, M.R. Milho: espaçamento e densidade. Agência Embrapa - Informação e Tecnologia. Disponível em:

http://www.agencia.cnptia.embrapa.br/gestor/milho/arvore/CONTAG01_49_168200511159.html, Acesso em: 21 de nov. 2013.

EMBRAPA - Empresa Brasileira de Pesquisa Agropecuária, Centro Nacional de Ciência do Solo. Manual de métodos de análise do solo. Rio de Janeiro, 1997. Não paginado.

FALLAHI, S.; RAOUFAT, M.H. Row-crop planter attachments in a conservation tillage system: A comparative study. Soil \& Tillage Research, Amsterdam, v.1, n.98, p.27-34, 2008.

FRABETTI, D.R.; RESENDE, C.R.; QUEIROZ, D. M.; FERNANDES, H.C.; SOLZA, C.M. Desenvolvimento e avaliação do desempenho de uma semeadora puncionadora para plantio direto de milho. Revista Brasileira Engenharia Agrícola \& Ambiental, Campina Grande, v.15, n.2, p.199204, 2011.

KOAKOSKI, A.; SOUZA, C.M.A. de; RAFULL, L.Z.L.; SOUZA, L.F. de; REIS, E.F. dos Desempenho de semeadora-adubadora utilizando-se dois mecanismos rompedores e três pressões da roda compactadora. Pesquisa Agropecuária Brasileira, Brasília, v.42, n.5, p.725-731, 2007.

LEVIEN, R.; FURLANI, C.E.A.; GAMERO, C.A.; CONTE, O.; CAVICHIOLI, F.A. Semeadura direta de milho com dois tipos de sulcadores de adubo, em nível e no sentido do declive do terreno Ciência Rural, Santa Maria, v.41, n.6, 2011.

MAHL, D.; FURLANI, C.E.A.; GAMERO, C.A. Efficiency of pneumatic and horizontal perforated disk meter mechanism in corn no-tillage seeders in soil with different mobilization reports.

Engenharia Agrícola, Jaboticabal, v.28, n.3, p.535-542, 2008.

PALMA, M.A.Z. Desenvolvimento e avaliação de ponteiras utilizadas em hastes sulcadoras de semeadoras para plantio direto. 2013. 112f. Tese (Doutorado em Engenharia Agrícola) Universidade Federal de Lavras, Lavras, 2013.

REICHERT, J.M.; REINERT, D.J.; SUZUKI, L.E.A.S.; HORN, R. Mecânica do solo. In: van LIER, Q.J., Ed. Física do solo. Viçosa: Sociedade Brasileira Ciência do Solo, 2010. p.30-102.

SANTOS, A.J.M.; GAMERO, C.A.; BACKES, C.; SALOMÃO, L.C.; BICUDO, S.J. Desempenho de discos de corte de semeadora-adubadora em diferentes quantidades de cobertura vegetal. Revista Energia na Agricultura, Botucatu, v.5, n.4, p.17-30, 2010.

SANTOS, A.P.; TOURINO, M.C.C.; VOLPATO, C.E.S. Qualidade de semeadura na implantação da cultura do milho por três semeadoras de plantio direto. Ciência Agrotécnica, Lavras, v.32, n.5, p.1601-1608, 2008.

SIQUEIRA, R.; CASÃO JÚNIOR, R. Trabalhador no cultivo de grãos e oleaginosas: máquinas para manejo de coberturas e semeadura no sistema de plantio direto. Curitiba: SENAR, 2004. (Coleção SENAR).

THEISEN, G.; BIANCHI, M.A. Semeadura com pouco revolvimento de solo como auxílio no manejo de plantas daninhas em milho. Planta Daninha, Viçosa, MG, v.28, n.1, p.93-102, 2010. 